\title{
Process Intensification for Ammonia Synthesis in Multibed Reactors with Fe-Wustite and $\mathrm{Ru} / \mathrm{C}$ Catalysts
}

\author{
Antonio Tripodi, Francesco Conte, and Ilenia Rossetti*
}

Cite This: Ind. Eng. Chem. Res. 2021, 60, 908-915

Read Online

ACCESS | Lill Metrics \& More | 回 Article Recommendations

ABSTRACT: An ammonia synthesis loop is designed using two different catalysts, namely, a Fe-based one from a wustite precursor and a $\mathrm{Ru} / \mathrm{C}$ sample. Previously established kinetic models have been used and implemented in a process simulator to investigate different feeding and quenching arrangements. A different array of series and parallel reactive stages is then proposed and optimal conditions for the feeding strategy and catalyst loading are discussed. It is found that loading the last reacting stages with $\mathrm{Ru} / \mathrm{C}$ (instead of Fewustite) always improved the ammonia yield when other conditions were fixed. Different feed-splitting, intercooling, and quenching options were tried to verify their effect on the heat duty of the reactor and the interplay between this aspect and the ammonia product fraction. Adopting mixed catalyst configuration allowed considerable energy savings both as lower duty for the recycle loop compressor and decreased heat exchange needs, boosting process intensification as one of the primary challenges for this reaction.

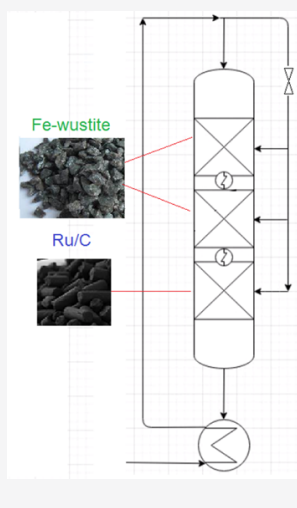

\section{INTRODUCTION}

Ammonia synthesis from gaseous nitrogen and hydrogen is a well-known reaction and established process, but its huge importance and very demanding reaction conditions have resulted in ongoing research studies for one century. ${ }^{1}$ The overall energetic balance and carbon dioxide footprint of the process depend, respectively, on the primary sources of nitrogen and hydrogen. ${ }^{2}$ Steam reforming is very energy intensive, accounting for $1.2 \%$ of the global primary energy demand and ca. $1.5 \mathrm{~kg} \mathrm{CO} / \mathrm{kg} \mathrm{NH}_{3}$ is produced, accounting for ca. $0.93 \%$ of global greenhouse gas emissions. ${ }^{3}$

The most widely used ammonia synthesis plants are based on the Haber-Bosch concept and can reach up to 2000 ton per day productivity in the super giant plants. However, very harsh conditions are needed, such as pressure between 90 and 300 bar, depending on the technology. A pressure increase favors both thermodynamics of the reaction and allows a higher temperature for condensation of ammonia, with easier separation even using cooling water.

The ammonia synthesis loop is integrated upstream with different processes to produce hydrogen, e.g., steam or autothermal reforming, gasification, etc., which rely on fossil sources. Despite the recent advances in electrochemical or photocatalytic nitrogen reduction methods, ${ }^{4,5}$ present day sustainable production is dependent mainly on the substitution of fossil hydrogen sources with renewable ones. ${ }^{6}$ Nevertheless, it is less likely that renewable technologies will be exploited in the near future and, mostly, they cannot fit the large-scale production plant, being mainly suited for delocalized smallscale installations. Therefore, the key to improving the sustainability of this process both from the environmental and economical point of view remains the intensification of the ammonia synthesis loop to improve the productivity under the same operating conditions or to achieve the same productivity under less demanding conditions, so to save resources and energy per ton of ammonia produced.

The different catalysts for ammonia synthesis have been recently reviewed. ${ }^{7}$ Furthermore, a comparison between different active phases ( $\mathrm{Co}, \mathrm{Ru}, \mathrm{Mo}$, and $\mathrm{Ni}$ ) and supports was recently proposed. ${ }^{8}$ Fe-based and Ru-based catalysts are state-of-the-art catalytic materials. ${ }^{9-12}$ In particular, Fe-based catalysts were originally obtained from magnetite, while in the last two decades, wustite is preferred as the precursor since it allows significantly higher conversion per pass at moderate space velocities. The wustite-based catalysts increase the catalytic activity by ca. $70 \%$ with respect to magnetite and they are currently the most advanced commercial iron catalyst with the highest activity and lower production cost in the world. By contrast, $\mathrm{Ru} / \mathrm{C}$ shows high activity below 400 ${ }^{\circ} \mathrm{C}^{13-15}$ and it is not inhibited by ammonia, so it can boost the conversion with respect to $\mathrm{Fe}$ after ammonia concentration has reached significant values. ${ }^{16}$ Commercial applications are present in the KAAP process, where the Ru-based catalyst is

Received: October 31, 2020

Revised: December 26, 2020

Accepted: December 29, 2020

Published: January 6, 2021 
10-20 times more active than traditional magnetite. KAAP allows lower synthesis loop pressure and offers lower capital costs, more competitive energy consumption, increased reliability, and lower maintenance costs. ${ }^{17}$ The main drawbacks of the $\mathrm{Ru} / \mathrm{C}$ catalyst are its cost and its inhibition by hydrogen. ${ }^{18}$ Therefore, a smart way to take advantage of the specific features of both catalytic systems is to join them in series in multibed configuration, which is an arrangement also suggested by the strong exothermicity of this equilibriumlimited reaction, which imposes to cool the reacting mixture along the bed. This is commonly achieved by separating the catalyst in multibed configuration with intercooling stages, leaving room for different coupling of catalytic materials.

The kinetic models adopted to calculate the reaction rate should represent the different features of the catalysts, accounting in different ways for the reactants' adsorption: in most cases, the partial pressure of $\mathrm{N}_{2}$ is considered sufficient to model this part of the mechanism, ${ }^{19}$ according to the fundamental work on the rate-determining steps by Temkin. ${ }^{20}$ More recent data interpolations add a rescaling Langmuir-type adsorption denominator ${ }^{15,16}$ to interpret and quantify the different adsorption behaviors of the reactants/products over $\mathrm{Fe}$ and Ru.

The reactor configurations belong essentially to three types: cooled, $^{21}$ adiabatic, ${ }^{22}$ and adiabatic-indirect cooling, ${ }^{23}$ and all of them have been considered in several computational studies aiming at the prediction of the optimal process management (see refs $24-28$ for a brief review) also in a comparative way. ${ }^{23}$ However, careful optimization of the reacting system is still the key for process intensification, implying the tight control of the temperature profile and the management of catalyst coupling to boost the conversion per pass and to achieve a better catalyst utilization.

Therefore, the scope of this work is to show how the use of different reactor assembly, sketched in Figure 1, cooling options, and catalyst couplings, modeled through proper kinetic equations for different materials, ${ }^{16}$ can effectively help to design, analyze, and compare such different options, leading to increased productivity or considerable energy savings.

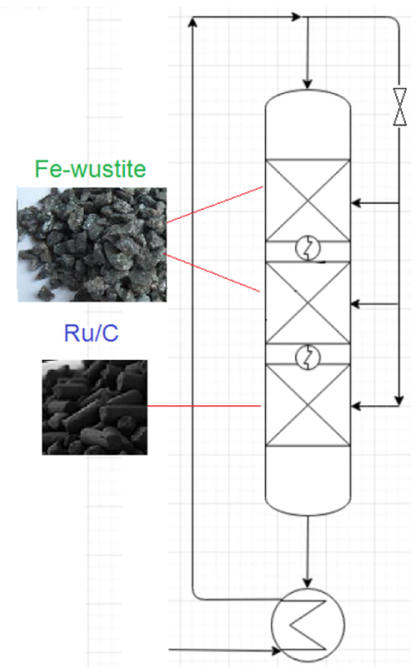

Figure 1. Conceptual layout of the three-bed ammonia synthesis reactor considered here.

\section{MODELS AND METHODS}

The catalysts selected are a commercial Fe-based (from wustite) catalyst, $^{11}$ tested preliminarily in our labs, and a $\mathrm{Ru} /$ C-based catalyst developed by our research group a few years ago and transferred to a company for development. ${ }^{1,16,29-33}$ Detailed characterization of the materials are reported in previous publications, specifically in refs $11,33-35$.

The adopted kinetic models for the ammonia synthesis rate are

$$
\begin{aligned}
q=k\left[K^{2} f_{\mathrm{N}_{2}}\left(\frac{f_{\mathrm{H}_{2}}^{2.25}}{f_{\mathrm{NH}_{3}}^{1.5}}\right)-\left(\frac{f_{\mathrm{NH}_{3}}^{0.5}}{f_{\mathrm{H}_{2}}^{0.75}}\right)\right] \\
(\mathrm{Fe}-\text { Wustite catalyst }) \\
q=k \frac{\left(f_{\mathrm{N}_{2}}\right)^{0.5}\left[\frac{\left(f_{\mathrm{H}_{2}}\right)^{0.375}}{\left(f_{\mathrm{NH}_{3}}\right)^{0.25}}\right]-\frac{1}{K}\left[\frac{\left(f_{\mathrm{NH}_{3}}\right)^{0.75}}{\left(f_{\mathrm{H}_{2}}\right)^{1.125}}\right]}{1+K_{\mathrm{H}_{2}}\left(f_{\mathrm{H}_{2}}\right)^{0.3}+K_{\mathrm{NH}_{3}}\left(f_{\mathrm{NH}_{3}}\right)^{0.2}} \quad(\mathrm{Ru} / \mathrm{C} \text { catalyst })
\end{aligned}
$$

whose details can be found in the already published studies. $^{15,16}$ This intrinsic kinetics is used to solve the steady-state plug-flow continuity equations (see the list of symbols for their meaning), expressed in the general form of material (for any $i$-th species) and energy balances, respectively, as

$$
\begin{aligned}
\frac{\partial C_{i}}{\partial t} & =-\left(\frac{F}{A C}\right) \frac{\partial C_{i}}{\partial x}+q_{i} \times \frac{m_{\mathrm{cat}}}{V(1-\varepsilon)}=0 \\
\frac{\partial T}{\partial t} & =-\left(\frac{F}{A C}\right) \frac{\partial T}{\partial x}+q_{i} \times \frac{m_{\mathrm{cat}}}{V(1-\varepsilon)} \times \frac{\Delta_{\mathrm{r}} H}{C_{\mathrm{p}}}=0
\end{aligned}
$$

with boundary conditions (superscript "0" indicates the reactor inlet as fixed by the process) and nil dependence on time for the steady-state conditions considered here

$$
\begin{aligned}
& {\left[\frac{\partial C_{i}}{\partial x}\right]_{x=0, L}=0\left[\frac{\partial T}{\partial x}\right]_{x=0, L} \quad \text { for any time }} \\
& C_{i}(x=0)=C_{i}^{0} T(x=0)=T^{0} \quad \text { for any time }
\end{aligned}
$$

The gas-solid transport kinetics and the diffusion through the catalyst's particle are not considered because they depend on very specific solid characteristics and hydraulic conditions of the bed, ${ }^{36}$ while this analysis is focused on the effect coming from more general aspects, such as the contact time and operative temperature and pressure. Furthermore, back mixing and axial dispersion are not considered since radial flow reactors often used with $\mathrm{Ru} / \mathrm{C}$ catalysts finely allow this approximation, with the path of the reactants limited across the catalyst layer and dispersion along this direction negligible.

The conversion was measured taking nitrogen as the reference component, and is indicated by

$$
X=1-\frac{w_{\mathrm{N}_{2}}}{w_{\mathrm{N}_{2}}^{0}}
$$

$r$ is also defined as "local conversion"

$$
r=\frac{\partial w_{\mathrm{NH}_{3}}}{\partial x / L}
$$

The mass and energy balances above were solved using the "rplug" block in the Aspen Plus simulator, again sufficiently 


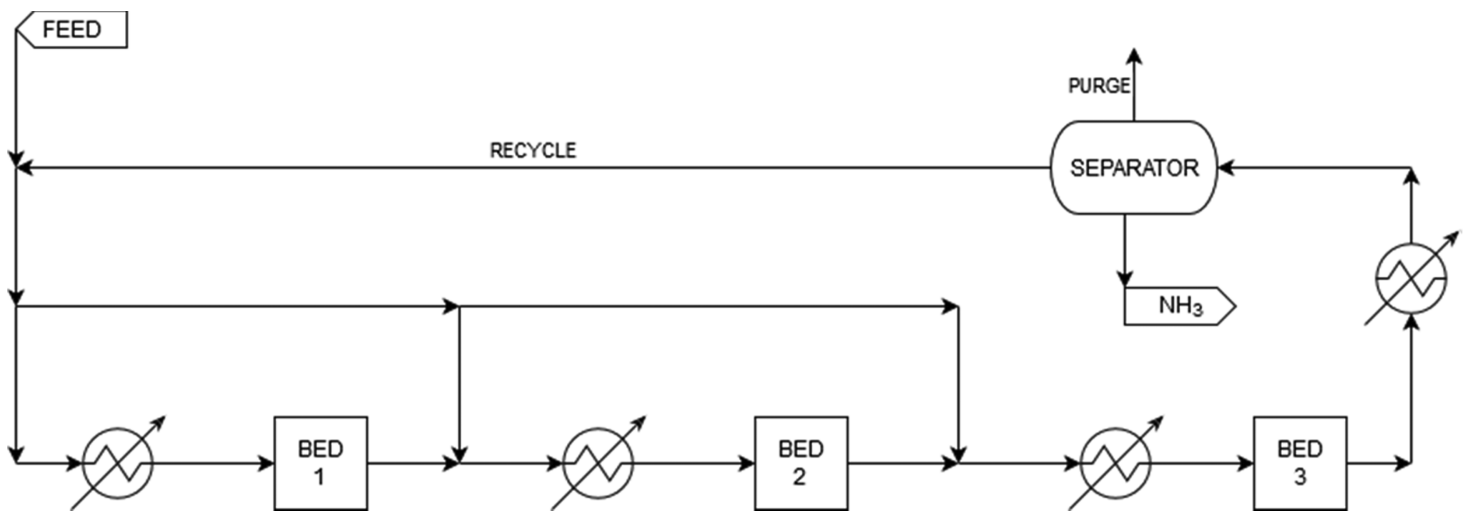

Figure 2. Three-stage reactor for ammonia synthesis with interstage cooling between adiabatic sections. Bed 3 contains either the Fe-wustite or Ru/ C catalyst, according to the case.

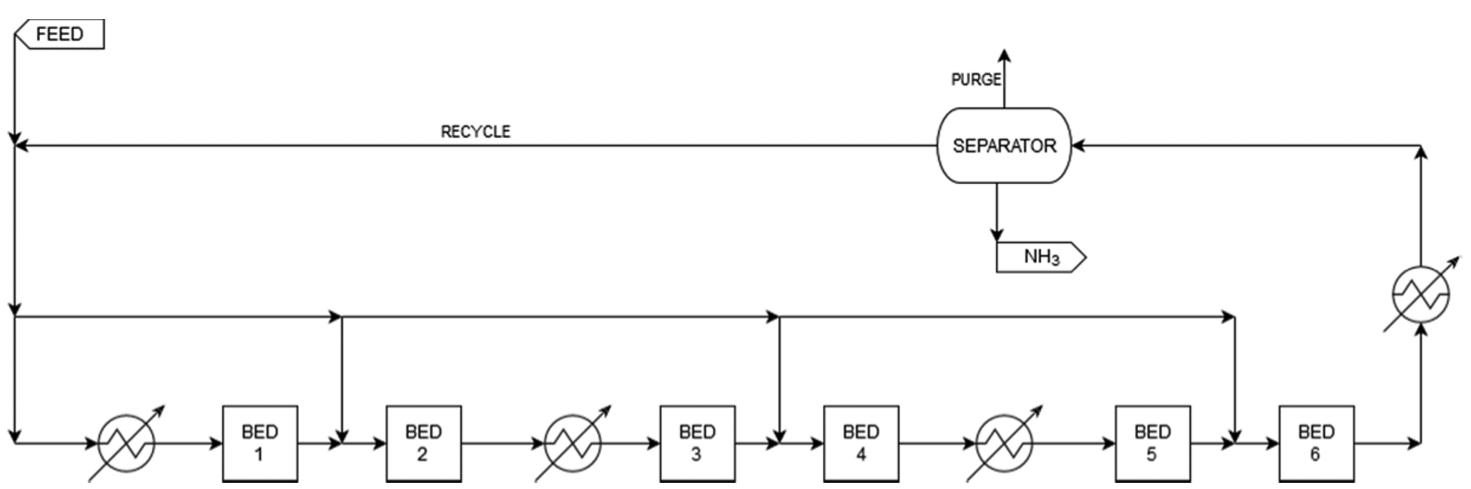

Figure 3. Six-stage full-scale reactor for ammonia synthesis with interstage cooling and quench between adiabatic sections. Beds 5-6 contain either the Fe-Wustite or $\mathrm{Ru} / \mathrm{C}$ catalyst, according to the case.

well representing radial flow reactors. The thermodynamic model chosen to describe the nonideality of the pressurized gas is the Soave-Redlich-Kwong equation of state (SRK EoS), checked for thermodynamic consistency with experimental data in previous work. ${ }^{16}$

The kinetic model has also been validated in the same previous work, considering a micropilot plant and reproducing the experimental data appropriately. Details are reported by Tripodi et al. ${ }^{16}$

Using a single unit of this type, it was possible to calculate the single-pass performances of a catalyst.

The simulation of a whole reactor was made by connecting multiple plug-flow stages together, each one now representing a single reactive bed. ${ }^{16,37-39}$ The configurations analyzed are sketched in Figures 2 and 3.

In these cases, the reactor was not fed with the fresh nitrogen-hydrogen mixture, but with the recycle stream obtained mixing the fresh feed and the vapors left after the separation of liquid ammonia. The separation was simulated as a vapor-liquid thermodynamic equilibrium stage at $0{ }^{\circ} \mathrm{C}$ (set in a previous study ${ }^{16}$ and achievable with a moderate refrigeration cycle), using the mixed models of SRK EoS for the gas-phase and the nonrandom two liquids (NRTL) model to compute nonideality for the liquid phase. This multiple-bed simulation is also done under the hypothesis of having the feed already pressurized but not at the reaction temperature: this means that the first heat exchanger in both Figures 2 and 3 also performs the role of the regenerative feed-to-product heat transfer unit usually foreseen in ammonia plants. ${ }^{40,41}$

\section{RESULTS}

The kinetic analysis on the per-pass conversion showed that the Fe-wustite catalyst was able to maintain a constant reaction rate until the conversion reached $75 \%$ of its limiting equilibrium value in adiabatic conditions at 200 bar. At 150 bar, the same behavior was found, even if with a lower conversion. The $\mathrm{Ru} / \mathrm{C}$ catalyst showed, instead, a very different kinetic feature because the ammonia production rate, initially low, increased until a maximum at about $65-70 \%$ of the equilibrium conversion (in adiabatic conditions), as represented in Figures 4-9. In particular, Figures 4 and 5 refer

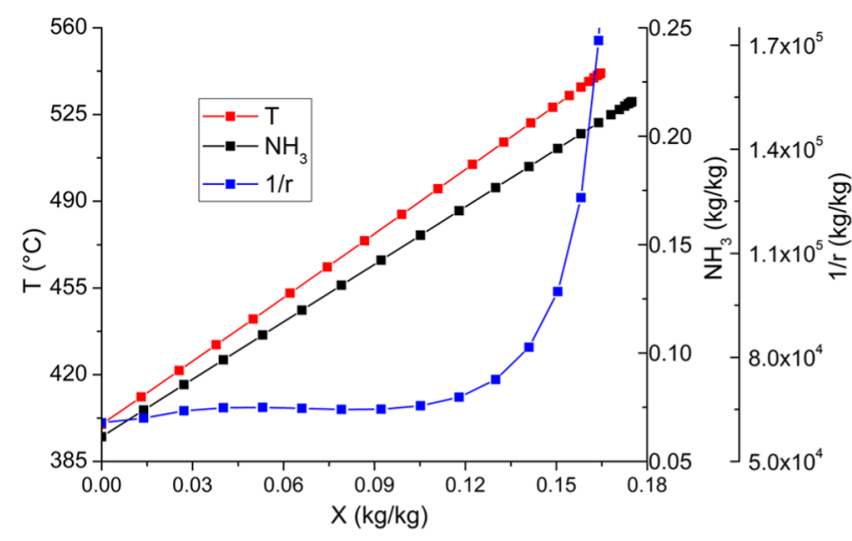

Figure 4. Correlation between the ammonia outlet concentration, conversion $(X)$, and temperature for the Fe-wustite catalyst. $P=200$ bar, $T=400{ }^{\circ} \mathrm{C}, \mathrm{N}_{2}: \mathrm{H}_{2}=1: 3 \mathrm{~mol} / \mathrm{mol}$, and GHSV $=15 \mathrm{~h}^{-1}$. 


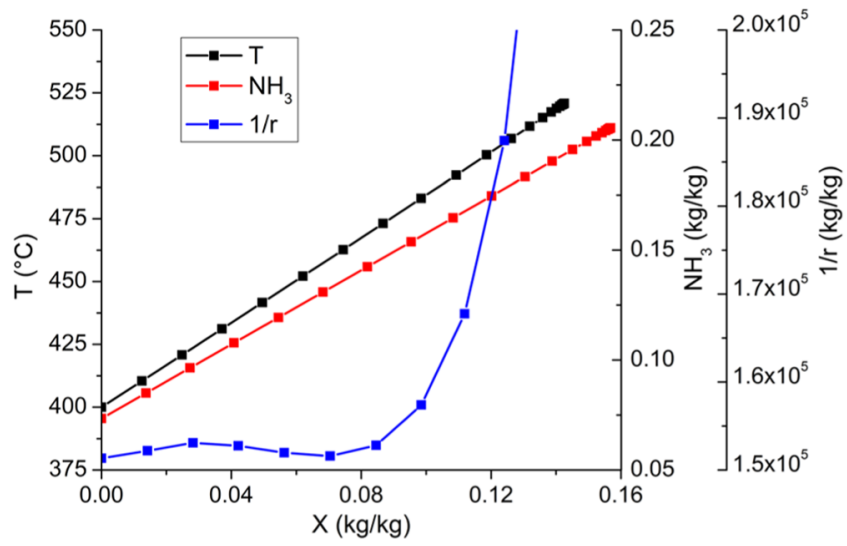

Figure 5. Correlation between the ammonia outlet concentration, conversion $(X)$, and temperature for the Fe-wustite catalyst. $P=150$ bar, $T=400{ }^{\circ} \mathrm{C}, \mathrm{N}_{2}: \mathrm{H}_{2}=1: 3 \mathrm{~mol} / \mathrm{mol}$, and GHSV $=7.5 \mathrm{~h}^{-1}$.

to the Fe-based catalyst operated adiabatically at 200 and 150 bar, respectively, with an inlet temperature of $400{ }^{\circ} \mathrm{C}$. The adiabatic temperature increase in both cases was higher than $100{ }^{\circ} \mathrm{C}$, progressively depressing the reaction rate (reported as local conversion $1 / r$ ) together with the increase of ammonia concentration. The latter attests above $20 \%$ per pass, which is indeed a good result with respect to literature data. ${ }^{3}$ One may also notice the different starting ammonia concentrations at different operating pressures of the loop. Higher pressure allows higher ammonia removal at the same temperature in the equilibrium separation stage. The same considerations hold for the $\mathrm{Ru} / \mathrm{C}$ catalyst (Figures 6 and 7 ).

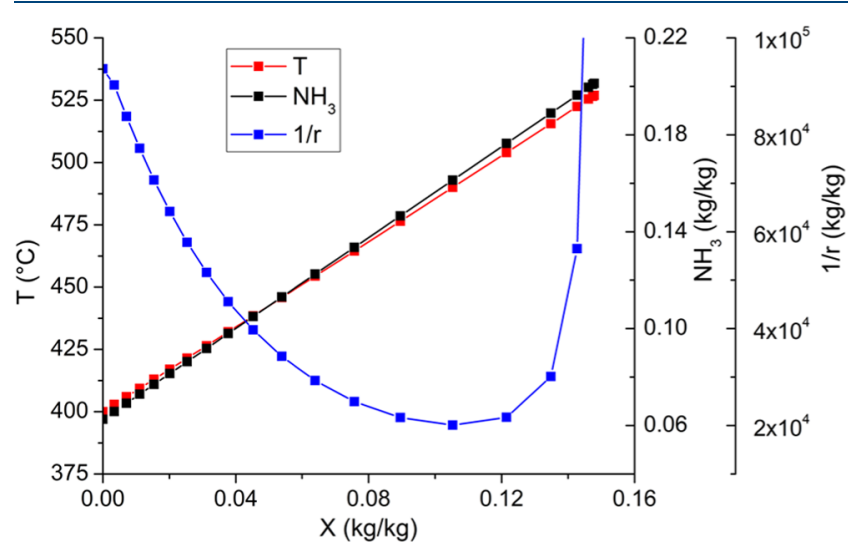

Figure 6. Correlation between the ammonia outlet concentration, conversion $(X)$, and temperature for the $\mathrm{Ru} / \mathrm{C}$ catalyst. $P=200$ bar, $T$ $=400{ }^{\circ} \mathrm{C}, \mathrm{N}_{2}: \mathrm{H}_{2}=1: 3 \mathrm{~mol} / \mathrm{mol}$, and GHSV $=42 \mathrm{~h}^{-1}$.

This kinetic analysis throws the basis for the employment of the $\mathrm{Ru} / \mathrm{C}$ catalyst only when the reacting mixture has already decreased its hydrogen content, overperforming the features of the Fe-wustite catalyst at relatively high conversion, when $\mathrm{Fe}$ is usually inhibited by the product, so flattening out the conversion pattern.

Furthermore, the analysis for different inlet starting temperatures, respectively, 400 and $450{ }^{\circ} \mathrm{C}$ (Figures 8 and 9), shows that the stoichiometric mixture is equilibrated with a space velocity (GHSV) of 50 or $250 \mathrm{~h}^{-1}$. Thus, higher inlet temperature limits the equilibrium conversion but allows higher space velocity, with nonobvious overall results on ammonia productivity.

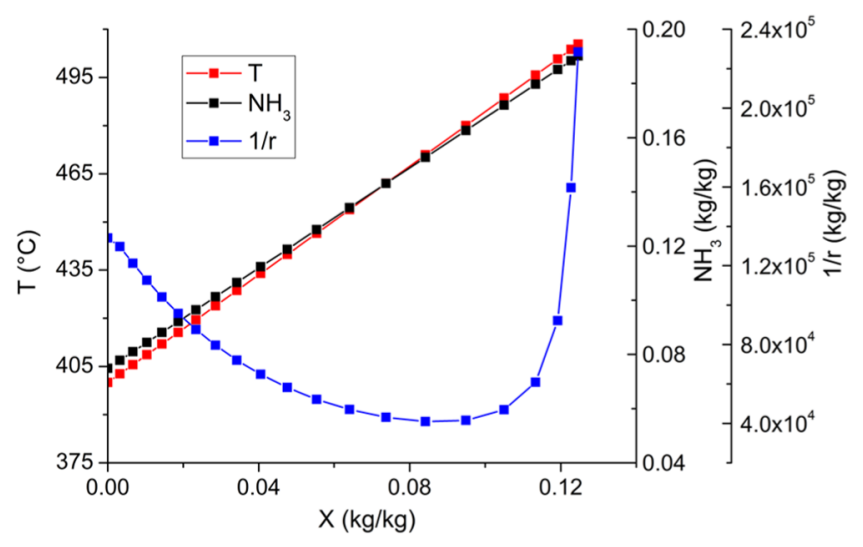

Figure 7. Correlation between the ammonia outlet concentration, conversion $(X)$, and temperature for the $\mathrm{Ru} / \mathrm{C}$ catalyst. $P=150 \mathrm{bar}, T$ $=400{ }^{\circ} \mathrm{C}, \mathrm{N}_{2}: \mathrm{H}_{2}=1: 3 \mathrm{~mol} / \mathrm{mol}$, and GHSV $=36 \mathrm{~h}^{-1}$.

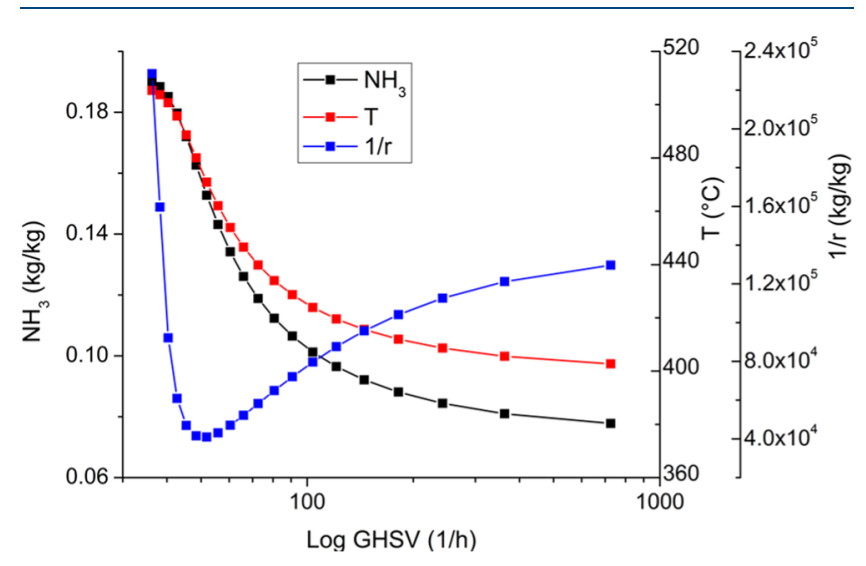

Figure 8. Correlation between the ammonia outlet concentration, space velocity (GHSV), and temperature for the Ru/C catalyst. $P=$ 150 bar, $T=400{ }^{\circ} \mathrm{C}$, and $\mathrm{N}_{2}: \mathrm{H}_{2}=1: 3 \mathrm{~mol} / \mathrm{mol}$.

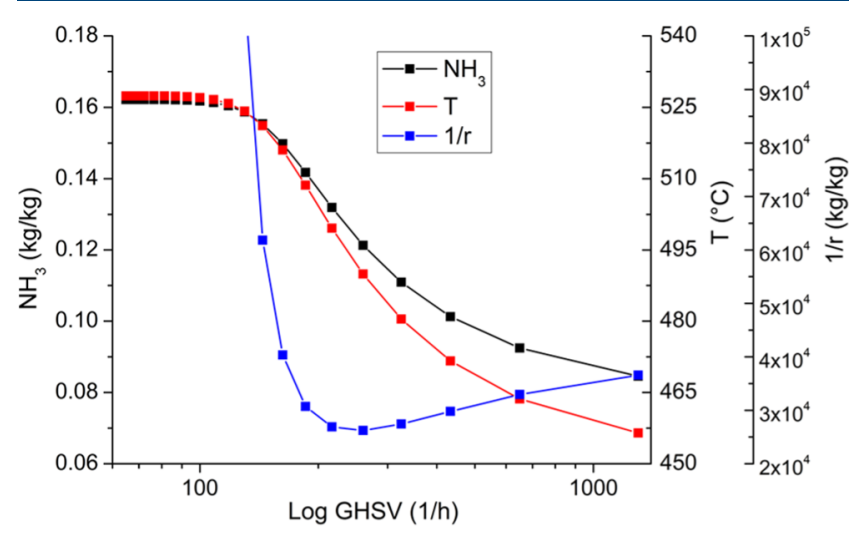

Figure 9. Correlation between the ammonia outlet concentration, space velocity (GHSV), and temperature for the Ru/C catalyst. $P=$ 150 bar, $T=450{ }^{\circ} \mathrm{C}$, and $\mathrm{N}_{2}: \mathrm{H}_{2}=1: 3 \mathrm{~mol} / \mathrm{mol}$.

The higher activity of $\mathrm{Ru} / \mathrm{C}$ vs Fe-wustite can be exploited in two ways: by reducing the overall catalytic load (this can be especially favorable with the most active but expensive material) or by decreasing the reaction temperature/pressure, saving energy and thus operating costs. Figures 10 and 11 synthetically show the outcome of the first approach. Fixing the conditions for two adiabatic Fe-wustite stages, if the third is loaded with $\mathrm{Ru} / \mathrm{C}$, then the conversion rate is about 8 times 


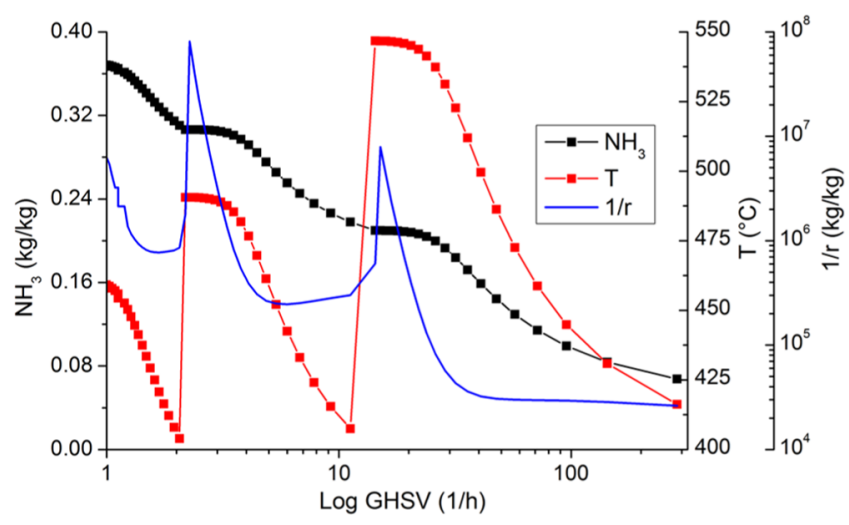

Figure 10. Ammonia yield and temperature profile for a reactor configuration exemplifying three wustite adiabatic beds in series. $P=$ $200 \mathrm{bar}, \mathrm{N}_{2}: \mathrm{H}_{2}=1: 3 \mathrm{~mol} / \mathrm{mol}$, and GHSV $=1 \mathrm{~h}^{-1}$.

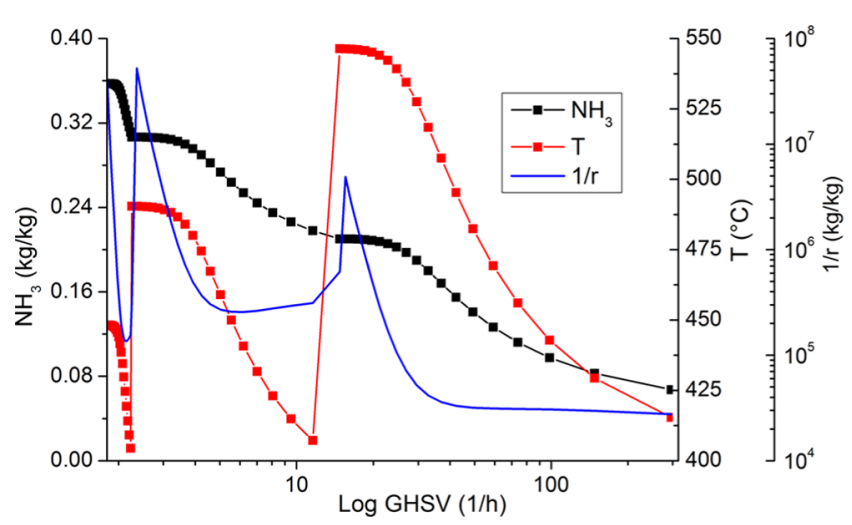

Figure 11. Ammonia yield and temperature profile for a reactor configuration exemplifying two wustite followed by one $\mathrm{Ru} / \mathrm{C}$ adiabatic beds in series. $P=200$ bar, $\mathrm{N}_{2}: \mathrm{H}_{2}=1: 3 \mathrm{~mol} / \mathrm{mol}$, and GHSV $=1.8 \mathrm{~h}^{-1}$.

higher and the equilibrium condition can be reached at higher GHSV, ensuring higher productivity.

The adiabatic temperature profiles are also traced in Figure 12 , where they are compared with possible heat-controlled reaction management. Lower temperatures would, in fact, require lower GHSVs to reach the same conversion but increase the equilibrium ammonia fraction reachable.

Under the hypothesis of achieving the desired, steadily increasing temperatures depicted in Figure 12 in the curves with the heat-controlled thermal profile (labeled "selected"), the effect of a feed-split thermal control strategy was also tested (results in Tables 1 and 2) to simulate the quench cooling option. Indeed, a common complementary approach to intercooling between consecutive catalytic beds is the possibility to quench the catalyst by feeding a warm portion of the feed, which is thus partialized and differently injected to control the adiabatic temperature increase along the bed.

As expected, when a part of the feed was directly sent to the last stage constituted by the Fe-wustite catalyst, the mixture sent to the separator was poorer in ammonia but its absolute yield was nearly constant because the kinetic rate expression takes advantage of the higher nitrogen and hydrogen fractions. When the third stage was loaded with $\mathrm{Ru} / \mathrm{C}$, the same trend was observed, but the same ammonia yield could be reached, in such a case, using only half the amount of the catalyst loaded in the first two stages. Generally, the fraction of recycle stream that can bypass the first stages must not exceed $1 / 3$ (at equal

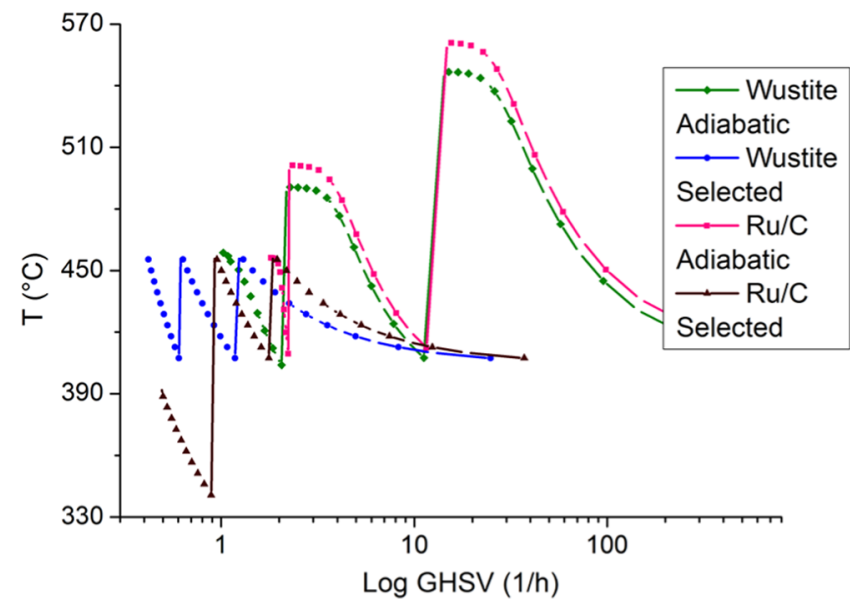

Figure 12. Temperature-GHSV plot for a three-stage reactor with different thermal profiles. $P=200$ bar, $\mathrm{N}_{2}: \mathrm{H}_{2}=1: 3 \mathrm{~mol} / \mathrm{mol}$, and GHSV $=0.4 \mathrm{~h}^{-1}$. "Selected" curves represent heat-controlled reaction management. Wustite refers to three catalyst beds in series containing the Fe-wustite catalyst, $\mathrm{Ru} / \mathrm{C}$ refers to two catalytic beds containing the $\mathrm{Fe}-\mathrm{Wustite}$ and the last one containing the $\mathrm{Ru} / \mathrm{C}$ catalysts.

loadings) and the higher yield was always found with no split at all.

Tables 3 and 4 present the analysis of the six-stage reactor represented in Figure 3, with or without $\mathrm{Ru} / \mathrm{C}$ in the last double bed. With respect to the three-stage configuration, the temperatures at each stage inlet were decreased, but then the thermal behavior was set as adiabatic to have a more realistic view of the phenomenon. This explains the decrease in the ammonia content at the separator; then, the nearly unchanged yield implies a larger recycle. In adiabatic conditions, anyway, the overall ammonia yield is also maintained when the feed is split, which opens the possibility of relaxing the cooling duties.

The last row represents, in fact, the split fractions needed to have null cooling duties after stages 2 and 4 (with the imposed inlet temperatures): this favorable condition can be met, granting ammonia yields comparable to the other cases.

The use of $\mathrm{Ru} / \mathrm{C}$ in the last catalyst bed, either in a threestage configuration with intercooling, or in a six-stage with intercooling and quenching, allows considerable savings in the recycle loop compressor and in the heat exchanger needs.

\section{CONCLUSIONS}

The benefits coming from the high activity and low inhibition by ammonia of a Ru-based catalyst have been investigated for a representative reactor setup, with adiabatic beds and multiple feed-splits and intercooling options.

Generally, the replacement of Fe-wustite with $\mathrm{Ru} / \mathrm{C}$ in the last bed improves the reactor productivity with lower catalytic loads in every stage. This is essentially due to the higher reaction rates achieved at high ammonia fractions that, in turn, allow us to adopt a relatively low temperature moving toward a more favorable equilibrium condition.

The three-stage simulation shows no benefits from the different feed-split policies if the temperature between each bed is managed independently. This comes from the fact that, provided that the catalyst is always sufficient to equilibrate the mixture, at the stoichiometric $\mathrm{H}_{2}: \mathrm{N}_{2}$ ratio, the role of temperature is dominant. On the other hand, when the feedsplit is also used as a cooling mean (as in the six-stages adiabatic calculation), its effect on the temperature cascade 
Table 1. Working Cases for Three Wustite Beds Connected in Series, 90 Tons of Catalyst Each, Operating at 200 Bar, and Equal Temperature Ramps from 400 to $450{ }^{\circ} \mathrm{C}^{a}$

$\begin{array}{lccccccc}\text { case } & S 1(\mathrm{~kg} / \mathrm{kg}) & S 2(\mathrm{~kg} / \mathrm{kg}) & w 1(\mathrm{~kg} / \mathrm{kg}) & w 2(\mathrm{~kg} / \mathrm{kg}) & w 3(\mathrm{~kg} / \mathrm{kg}) & \mathrm{NH}_{3} \text { prod }(\mathrm{t} / \mathrm{h}) & \text { reactor duties }(\mathrm{MW} \text { th }) \\ 1 & 1 & 0 & 0.364 & 0.406 & 0.421 & 41.7 & 42.3 /-5.17 /-5.15 \\ 2 & 0.5 & 0.5 & 0.398 & 0.372 & 0.408 & 41.5 & 21.9 / 19.3 /-5.34 \\ 3 & 0.5 & 0 & 0.394 & 0.419 & 0.368 & 40.8 & 24.5 /-2.98 / 21.7 \\ 4 & 0.25 & 0.25 & 0.41 & 0.399 & 0.366 & 40.7 & 12.3 / 10.9 / 21.8 \\ 5 & 0.33 & 0.33 & 0.406 & 0.389 & 0.377 & 40.9 & 15.8 / 13.9 / 12.5\end{array}$

a" $S$ " is the split fraction at the feed distributors and $w$ the ammonia weight fraction exiting a stage. Duties refer to thermal ones for the reactors and for the compressor to recycle the unreacted gas.

Table 2. Working Cases for Two Wustite Beds (50 Ton Each) Followed by One Ru/C Bed (90 Ton) Connected in Series, Operating at $200 \mathrm{Bar}$, and Temperature Ramps from 400 to $450{ }^{\circ} \mathrm{C}$ for Fe-Wustite and $340-390{ }^{\circ} \mathrm{C}$ for $\mathrm{Ru} / \mathrm{C}^{a}$

$\begin{array}{lcccccccc}\text { case } & S 1(\mathrm{~kg} / \mathrm{kg}) & S 2(\mathrm{~kg} / \mathrm{kg}) & w 1(\mathrm{~kg} / \mathrm{kg}) & w 2(\mathrm{~kg} / \mathrm{kg}) & w 3(\mathrm{~kg} / \mathrm{kg}) & \mathrm{NH}_{3} \text { prod }(\mathrm{t} / \mathrm{h}) & \text { reactor duties }\left(\mathrm{MW}_{\mathrm{th}}\right) & \text { recycle compressor duty }(\mathrm{kW} \mathrm{el}) \\ 1 & 1 & 0 & 0.335 & 0.385 & 0.500 & 42.7 & 35.1 /-4.32 /-9.41 & 56.9 \\ 2 & 0.5 & 0.5 & 0.379 & 0.347 & 0.487 & 42.5 & 18.0 / 15.9 /-9.72 & 60.0 \\ 3 & 0.5 & 0 & 0.373 & 0.411 & 0.439 & 41.9 & 20.2 /-2.47 / 1139 & 73.6 \\ 4 & 0.25 & 0.25 & 0.403 & 0.381 & 0.431 & 41.8 & 10.3 / 9.10 / 12.0 & 75.9 \\ 5 & 0.33 & 0.33 & 0.395 & 0.368 & 0.452 & 42.1 & 12.9 / 11.4 / 4.42 & 69.5\end{array}$

${ }^{a}$ Duties refer to thermal ones for the reactors and for the compressor to recycle the unreacted gas.

Table 3. Working Cases for Six Adiabatic Beds Loaded with Fe-Wustite, 9-20-40-70-80-90 Tons of Catalyst, Respectively, Operating at $200 \mathrm{Bar}$, Inlet Temperatures Fixed at $400{ }^{\circ} \mathrm{C}$ with Intercooling between Each Couple of Beds (See Figure 3$)^{a}$

\begin{tabular}{|c|c|c|c|c|c|c|c|c|c|}
\hline case & $\begin{array}{c}S 1 \\
(\mathrm{~kg} / \mathrm{kg})\end{array}$ & $\begin{array}{c}S 2 \\
(\mathrm{~kg} / \mathrm{kg})\end{array}$ & $\begin{array}{c}S 3 \\
(\mathrm{~kg} / \mathrm{kg})\end{array}$ & $\begin{array}{c}w 2 \\
(\mathrm{~kg} / \mathrm{kg})\end{array}$ & $\begin{array}{c}w 4 \\
(\mathrm{~kg} / \mathrm{kg})\end{array}$ & $\begin{array}{c}w 6 \\
(\mathrm{~kg} / \mathrm{kg})\end{array}$ & $\begin{array}{l}\mathrm{NH}_{3} \text { prod } \\
(\mathrm{t} / \mathrm{h})\end{array}$ & reactor duties $\left(\mathrm{MW}_{\mathrm{th}}\right)$ & $\begin{array}{l}\text { recycle compressor duty } \\
\qquad\left(\mathrm{kW}_{\mathrm{el}}\right)\end{array}$ \\
\hline 1 & 1.0 & 0.0 & 0.0 & 0.21 & 0.306 & 0.370 & 40.8 & $48.7 /-17.9 /-10.9$ & 99.1 \\
\hline 2 & 0.50 & 0.25 & 0.25 & 0.264 & 0.327 & 0.384 & 41.1 & $23.4 /-5.62 /-0.952$ & 93.2 \\
\hline 3 & 0.25 & 0.25 & 0.50 & 0.141 & 0.164 & 0.278 & 38.3 & $16.8 / 10.3 / 23.6$ & 156 \\
\hline 4 & 0.40 & 0.25 & 0.25 & 0.213 & 0.341 & 0.402 & 41.4 & $17.8 / 0.0682 /-4.92$ & 86.1 \\
\hline 5 & 0.33 & 0.25 & 0.30 & 0.17 & 0.279 & 0.368 & 40.8 & $16.2 / 4.45 /-0.192$ & 100 \\
\hline 6 & 0.40 & 0.24 & 0.27 & 0.22 & 0.304 & 0.379 & 41.0 & $19.0 /-0.545 /-0.644$ & 95.0 \\
\hline
\end{tabular}

${ }^{a}$ Duties refer to thermal ones for the reactors and for the compressor to recycle the unreacted gas.

Table 4. Working Cases for Four Adiabatic Beds Loaded with Fe-Wustite Followed by Two Loaded with Ru/C, 7.2-16-32-5640-65 tons of Catalyst in Each Stage, Operating at 200 bar, Inlet Temperatures Fixed at 400-400-340 ${ }^{\circ} \mathrm{C}$ for Each Couple of Beds $^{a}$

\begin{tabular}{|c|c|c|c|c|c|c|c|c|c|}
\hline case & $\begin{array}{c}S 1 \\
(\mathrm{~kg} / \mathrm{kg})\end{array}$ & $\begin{array}{c}S 2 \\
(\mathrm{~kg} / \mathrm{kg})\end{array}$ & $\begin{array}{c}S 3 \\
(\mathrm{~kg} / \mathrm{kg})\end{array}$ & $\begin{array}{c}w 2 \\
(\mathrm{~kg} / \mathrm{kg})\end{array}$ & $\begin{array}{c}w 4 \\
(\mathrm{~kg} / \mathrm{kg})\end{array}$ & $\begin{array}{c}w 6 \\
(\mathrm{~kg} / \mathrm{kg})\end{array}$ & $\begin{array}{l}\mathrm{NH}_{3} \text { prod } \\
(\mathrm{t} / \mathrm{h})\end{array}$ & reactor duties $\left(\mathrm{MW}_{\mathrm{th}}\right)$ & $\begin{array}{l}\text { recycle compressor duty } \\
\qquad\left(\mathrm{kW}_{\mathrm{el}}\right)\end{array}$ \\
\hline 1 & 1.0 & 0.0 & 0.0 & 0.208 & 0.305 & 0.400 & 41.4 & $44.7 /-16.5 /-16.6$ & 86.5 \\
\hline 2 & 0.50 & 0.25 & 0.25 & 0.247 & 0.32 & 0.41 & 41.5 & $21.7 /-4.15 /-7.87$ & 82.9 \\
\hline 3 & 0.25 & 0.25 & 0.50 & 0.139 & 0.162 & 0.304 & 39.2 & $15.2 / 9.31 / 12.2$ & 136 \\
\hline 4 & 0.40 & 0.25 & 0.25 & 0.200 & 0.331 & 0.424 & 41.7 & $16.8 / 7.53 /-10.1$ & 78.2 \\
\hline 5 & 0.33 & 0.25 & 0.30 & 0.164 & 0.264 & 0.385 & 41.1 & $15.4 / 4.50 /-5.21$ & 92.8 \\
\hline 6 & 0.40 & 0.23 & 0.33 & 0.206 & 0.244 & 0.363 & 40.7 & $19.9 / 0.0865 /-0.521$ & 102 \\
\hline
\end{tabular}

${ }^{a}$ Duties refer to thermal ones for the reactors and for the compressor to recycle the unreacted gas.

helps to shift the system to higher ammonia content with reduced cooling duties.

\section{AUTHOR INFORMATION}

\section{Corresponding Author}

Ilenia Rossetti - Chemical Plants and Industrial Chemistry Group, Dipartimento di Chimica, Università degli Studi di Milano, INSTM Milano Università-Unit, CNR-ISTM, 20133 Milano, Italy; ㅇoㅇid.org/0000-0001-5882-5011; Email: ilenia.rossetti@unimi.it; Fax: +39-02-50314300

\section{Authors}

Antonio Tripodi - Chemical Plants and Industrial Chemistry Group, Dipartimento di Chimica, Università degli Studi di
Milano, INSTM Milano Università-Unit, CNR-ISTM, 20133 Milano, Italy

Francesco Conte - Chemical Plants and Industrial Chemistry Group, Dipartimento di Chimica, Università degli Studi di Milano, INSTM Milano Università-Unit, CNR-ISTM, 20133 Milano, Italy

Complete contact information is available at: https://pubs.acs.org/10.1021/acs.iecr.0c05350

\section{Notes}

The authors declare no competing financial interest. 


\section{ACKNOWLEDGMENTS}

The authors gratefully acknowledge the valuable help of Riad Akhundzada for processing the simulation cases.

\section{LIST OF SYMBOLS}

A hydraulic section $\left(\mathrm{m}^{2}\right)$

C mole concentration $\left(\mathrm{kmol} / \mathrm{m}^{3}\right)$

$C_{\mathrm{p}}$ heat capacity $\left(\mathrm{kJ} \cdot \mathrm{kmol}^{-1} \cdot \mathrm{K}^{-1}\right)$

$\varepsilon \quad$ void fraction $\left(\mathrm{m}_{\text {void }}{ }^{3} / \mathrm{m}_{\text {tot }}{ }^{3}\right)$

$f$ fugacity $(\mathrm{Pa})$

$F$ mole flow $(\mathrm{kmol} / \mathrm{h})$

$\Delta_{\mathrm{r}} H$ reaction heat $(\mathrm{kJ} / \mathrm{kmol})$

$k \quad$ kinetic constant $\left(\mathrm{kmol} \cdot \mathrm{kg} \cdot \mathrm{cat}^{-1} \cdot \mathrm{h}^{-1} \cdot \mathrm{Pa}^{n}\right)$

$K$ equilibrium constant $\left(\mathrm{Pa}^{m}\right)$

$L$ reactor length $(\mathrm{m})$

$w$ mass fraction $(\mathrm{kg} / \mathrm{kg})$

$m$ catalyst load ( $\mathrm{kg})$

$q$ reaction rate $\left(\mathrm{kmol} \cdot \mathrm{kg} \cdot \mathrm{cat}^{-1} \cdot \mathrm{h}^{-1}\right)$

$r \quad$ local conversion $\frac{\partial w_{\mathrm{NH}_{3}}}{\partial x / L}$

$S \quad$ split fraction $(\mathrm{kg} / \mathrm{kg})$

$t$ time (h)

$T$ temperature (K)

$V$ reactor volume $\left(\mathrm{m}^{3}\right)$

$x$ axial coordinate $(\mathrm{m})$

$\mathrm{X}$ conversion $(\mathrm{kg} / \mathrm{kg})$

\section{REFERENCES}

(1) Rossetti, I. Reactor Design, Modelling and Process Intensification for Ammonia Synthesis. In Sustainable Ammonia Production, Series Green Energy and Technology; Springer Nature Switzerland AG: Charm, Switzerland, 2020; pp 17-48.

(2) Lan, R.; Alkhazmi, K. A.; Amar, I. A.; Tao, S. Synthesis of Ammonia Directly from Wet Air at Intermediate Temperature. Appl. Catal., B 2014, 152-153, 212-217.

(3) Gilbert, P.; Thornley, P. Energy and Carbon Balance of Ammonia Production from Biomass Gasification. In Poster at Bio-Ten Conference, Birmingham, 2010; pp 1-9.

(4) Yiokari, C. G.; Pitselis, G. E.; Polydoros, D. G.; Katsaounis, A. D.; Vayenas, C. G. High-Pressure Electrochemical Promotion of Ammonia Synthesis over an Industrial Iron Catalyst. J. Phys. Chem. A 2000, 104, 10600-10602.

(5) Yamauchi, M.; Abe, R.; Tsukuda, T.; Kato, K.; Takata, M. Highly Selective Ammonia Synthesis from Nitrate with Photocatalytically Generated Hydrogen on CuPd/TiO 2. J. Am. Chem. Soc. 2011, 133, $1150-1152$.

(6) Parthasarathy, P.; Narayanan, K. S. Hydrogen Production from Steam Gasification of Biomass: Influence of Process Parameters on Hydrogen Yield - A Review. Renewable Energy 2014, 66, 570-579.

(7) Inamuddin, R.; Boddula, A. M.; Asiri, E. Sustainable Ammonia Production; Green Energy and Technology; Springer Nature Switzerland AG: Charm, Switzerland, 2020.

(8) Daisley, A.; Hargreaves, J. S. J.; Hermann, R.; Poya, Y.; Wang, Y. A Comparison of the Activities of Various Supported Catalysts for Ammonia Synthesis. Catal. Today 2020, 357, 534-540.

(9) Liu, H.-Z.; Li, X.-N.; Hu, Z.-N. Development of Novel Low Temperature and Low Pressure Ammonia Synthesis Catalyst. Appl. Catal., A 1996, 142, 209-222.

(10) Liu, H.; Li, X. N. Study on Mechanism of High Activity of Fe1XO Based Catalyst for Ammonia Synthesis. Chin. J. Catal. 2005, 26, 79-86.

(11) Pernicone, N.; Ferrero, F.; Rossetti, I.; Forni, L.; Canton, P.; Riello, P.; Fagherazzi, G.; Signoretto, M.; Pinna, F. Wustite as a New Precursor of Industrial Ammonia Synthesis Catalysts. Appl. Catal., A 2003, 251, 121-129.
(12) Rossetti, I.; Pernicone, N.; Forni, L. Graphitised Carbon as Support for $\mathrm{Ru} / \mathrm{C}$ Ammonia Synthesis Catalyst. Catal. Today 2005, 102-103, 219-224.

(13) Aika, K.; Hori, H.; Ozaki, A. Activation of Nitrogen by Alkali Metal Promoted Transition Metal I. Ammonia Synthesis over Ruthenium Promoted by Alkali Metal. J. Catal. 1972, 27, 424-431.

(14) Forni, L.; Molinari, D.; Rossetti, I.; Pernicone, N. CarbonSupported Promoted $\mathrm{Ru}$ Catalyst for Ammonia Synthesis. Appl. Catal., A 1999, 269-275.

(15) Rossetti, I.; Pernicone, N.; Ferrero, F.; Forni, L. Kinetic Study of Ammonia Synthesis on a Promoted Ru/C Catalyst. Ind. Eng. Chem. Res. 2006, 45, 4150-4155.

(16) Tripodi, A.; Compagnoni, M.; Bahadori, E.; Rossetti, I. Process Simulation of Ammonia Synthesis over Optimized $\mathrm{Ru} / \mathrm{C}$ Catalyst and Multibed $\mathrm{Fe}+\mathrm{Ru}$ Configurations. J. Ind. Eng. Chem. 2018, 66, 176186.

(17) https://halliburtoncontracts.com.theyesmen.org/kbr/ hydroChem/fertSynGas/kaapPlusAmmoniaProcess.html.

(18) Liu, H. Ammonia Synthesis Catalysts. Innovation and Practice; Chemical Industry Press, 2013.

(19) Dyson, D. C.; Simon, J. M. A Kinetic Expression with Diffusion Correction for Ammonia Synthesis on Industrial Catalyst. Ind. Eng. Chem. Fundam. 1968, 7, 605-610.

(20) Temkin, M. I.; Pyzhev, V. Kinetics of Ammonia Synthesis on Promoted Iron Catalysts. Acta Physicochim. URSS 1940, 12, 327-356.

(21) Baddour, R. F.; Brian, P. L. T.; Logeais, B. A.; Eymery, J. P. Steady-State Simulation of an Ammonia Synthesis Converter. Chem. Eng. Sci. 1965, 20, 281-292.

(22) Noe, S. A. Horizontal Ammonia Converter Converter Adapted for High Activity Catalyst. EP0958858A2, 1999.

(23) Khademi, M. H.; Sabbaghi, R. S. Comparison between Three Types of Ammonia Synthesis Reactor Configurations in Terms of Cooling Methods. Chem. Eng. Res. Des. 2017, 128, 306-317.

(24) Babu, B. V.; Angira, R. Optimal Design of an Auto-Thermal Ammonia Synthesis Reactor. Comput. Chem. Eng. 2005, 29, 10411045.

(25) Gaines, L. D. Optimal Temperatures for Ammonia Synthesis Converters. Ind. Eng. Chem. Process Des. Dev. 1977, 16, 381-389.

(26) Reddy, K. V.; Husain, A. Modeling and Simulation of an Ammonia Synthesis Loop. Ind. Eng. Chem. Process Des. Dev. 1982, 21, 359-367.

(27) Elnashaie, S. S.; Abashar, M. E.; Al-Ubaid, A. S. Simulation and Optimization of an Industrial Ammonia Reactor. Ind. Eng. Chem. Res. 1988, 27, 2015-2022.

(28) Dashti, A.; Marvast, M. A. Modeling and Simulation of Ammonia Synthesis Reactor. Pet. Coal 2006, 48, 15-23.

(29) Rossetti, I.; Forni, L. Effect of Ru Loading and of Ru Precursor in Ru/C Catalysts for Ammonia Synthesis. Appl. Catal., A 2005, 282, $315-320$.

(30) Forni, L.; Molinari, D.; Rossetti, I.; Pernicone, N. CarbonSupported Promoted Ru Catalyst for Ammonia Synthesis. Appl. Catal., A 1999, 185, 269-275.

(31) Rossetti, I.; Pernicone, N.; Forni, L. Graphitised Carbon as Support for Ru/C Ammonia Synthesis Catalyst. Catal. Today 2005, 102-103, 219-224.

(32) Rossetti, I.; Pernicone, N.; Forni, L. Promoters Effect in Ru/C Ammonia Synthesis Catalyst. Appl. Catal., A 2001, 208, 271-278.

(33) Rossetti, I.; Mangiarini, F.; Forni, L. Promoters State and Catalyst Activation during Ammonia Synthesis over Ru/C. Appl. Catal., A 2007, 323, 219-225.

(34) Rossetti, I.; Pernicone, N.; Forni, L. Characterisation of Ru/C Catalysts for Ammonia Synthesis by Oxygen Chemisorption. Appl. Catal., A 2003, 248, 97-103.

(35) Rossetti, I.; Sordelli, L.; Ghigna, P.; Pin, S.; Scavini, M.; Forni, L. EXAFS-XANES Evidence of in Situ Cesium Reduction in Cs-Ru/C Catalysts for Ammonia Synthesis. Inorg. Chem. 2011, 50, 3757-3765.

(36) Li, T.; Xu, M. S.; Zhu, B. C.; Fang, D. Y.; Ying, W. Y. ReactionDiffusion Model for Irregularly Shaped Ammonia Synthesis Catalyst 
and Its Verification under High Pressure. Ind. Eng. Chem. Res. 2009, 48, 8926-8933.

(37) Singh, C. P. P.; Saraf, D. N. Simulation of Ammonia Synthesis Reactors. Ind. Eng. Chem. Process Des. Dev. 1979, 18, 364-370.

(38) Domański, P. D.; Golonka, S.; Jankowski, R.; Kalbarczyk, P.; Moszowski, B. Control Rehabilitation Impact on Production Efficiency of Ammonia Synthesis Installation. Ind. Eng. Chem. Res. 2016, 55, 10366-10376.

(39) Zhang, C.; Vasudevan, S.; Rangaiah, G. P. Plantwide Control System Design and Performance Evaluation for Ammonia Synthesis Process. Ind. Eng. Chem. Res. 2010, 49, 12538-12547.

(40) Izzat, I. C.; Ulrike, K. Optimisation of the Autothermal $\mathrm{NH}_{3}$ Production Process for Power-to-Ammonia. Processes 2020, 8, 38.

(41) Pinto, A. Ammonia Synthesis Plant. U.S. Patent 5,032,3641991. 